\title{
Response Leaners to BIPA Learning Based Culture
}

\author{
Isah Cahyani ${ }^{1}$, Siti Amila Rafiani Silmi ${ }^{2}$ \\ ${ }^{12}$ Universitas Pendidikan Indonesia \\ ${ }^{1}$ isahcahyani@upi.edu, ${ }^{2}$ ddsilmi@gmail.com
}

\begin{abstract}
Learning languages through culture is one of the strategic steps that can be applied in BIPA-based learning culture. With this, BIPA learners feel more familiar with Indonesia rich culture. BIPA students are very enthusiastic and interactive in learning. Their experience is enhanced by participating in every cultural activity in the form of workshops and games. With this learning, they felt helped to interact and adapt in Indonesia. Therefore, BIPA learning content should contain the inculcation of Indonesian cultural values so that BIPA learning is not only intended for learners to master verbal language but the concept of Indonesian culture as an important component for foreign learners to know. Furthermore, the BIPA learning based on culture is expected to help the process of internationalization of Indonesian language and culture. Culture-based BIPA learning has received positive responses from BIPA learners, especially in this case students from the Singapore Ministry.
\end{abstract}

Keywords: learner response, BIPA learning, culture based.

\section{PENDAHULUAN}

Bahasa Indonesia merupakan salah satu bahasa di dunia yang berkembang pesat di abad ke-20 ini. Pengajaran bahasa Indonesia terus mengalami peningkatan baik di dalam maupun di luar negeri. Dengan perkembangan hubungan antara Indonesia dengan negara lain dalam bidang pendidikan militer, ekonomi, budaya, dan pariwisata menyebabkan Indonesia semakin dikenal negara lain. Dengan demikian, makin besar dirasakan orang asing untuk belajar bahasa Indonesia. Oleh karena itu, jenis dan jenjang pendidikan atau kursus pun beragam. Pendekatan dan jenis pengajaran biasanya bersifat umum. BIPA merupakan isu penting dalam perencanaan bahasa Indonesia [1]. Pengajaran Bahasa Indonesia bagi Penutur Asing (BIPA) akan menjadi daya tarik dan menciptakan UPI sebagai World Class University (WCU).

BIPA semakin berkembang. Hal ini dipaparkan dalam situs Dikti bahwa minat mahasiswa asing yang mengikuti program darmasiswa semakin meningkat. Program Darmasiswa merupakan program beasiswa pemerintah Indonesia untuk negara-negara anggota ASEAN yang telah dimulai sejak 1974. Program imi ditujukan bagi mahasiswa asing yang ingin belajar bahasa Indonesia, kesenian, musik, dan kerajinan di Indonesia. Pada awal 1990 program diperluas dengan menyertakan mahasiswa asingyang berasal dari Australia, Canada, Perancis, Jerman, Hungaria, Jepang, Meksiko, Belanda, Norwegia, Polandia, Swedia, dan Amerika Serikat. Para mahasiswa dapat memilih untuk belajar di salah satu dari 44 universitas di Indonesia yang berpartisipasi dalam program tersebut [2]. Pada Kongres Bahasa Indonesia VI (1993) teramati bahwa pengajaran 
BIPA di luar negeri (khususnya Australia, Amerika, Rusia, dan Korea memperlihatkan keragaman dalam orientasi pengajaran, penyediaan materi ajar, dan manajemen pelatihan [1]. Terkait dengan maksud dan tujuan pembelajaran BIPA serta keterampilan yang diharapkan dimiliki oleh setiap pembelajar bahasa, seperti yang telah dijabarkan di atas, pembelajaran BIPA masih banyak terkendala, diantaranya belum adanya bahan ajar standar. Secara faktual berbicara mengenai bahan ajar pembelajaran BIPA, sampai dengan saat ini ternyata belum ada bahan ajar BIPA yang dijadikan materi ajar standar. Selama ini penyelenggara pendidikan memiliki kebebasan untuk menyusun bahan ajarnya sendiri. Dalam penyusunannya, standar bahan ajar yang digunakan tersebut disandarkan pada tujuan agar dapat menampung berbagai perkembangan penggunaan bahasa. Misalnya pendekatan terhadap orang yang belajar bahasa, mereka tidak lagi dipandang sebagai objek, tetapi sebagai subjek (pelaku) dalam proses belajar bahasa [3]. Segala kegiatan dalam pembelajaran bahasa, harus berpusat pada mereka yang belajar bahasa. Sebagai bahan ajar, Iskandarwassid dan Sunendar mengemukakan bahwa bahasa tidak dipelajari sebagai bagianbagian, tetapi dipelajari sebagai satu keutuhan, sesuai dengan bidang pemakaiannya [3]. Namun sayangnya tidak banyak yang menyadari dan melakukan pengembangan sistem pengajaran secara konsisten, bahwa setiap siswa BIPA menuntut kegiatan belajar (bukan kegiatan mengajar) yang menarik dan bermakna. Kegiatan belajar yang menarik saja tidak cukup jika bahan diajarkan kepada siswa tidak bermakna. Sebaliknya, walaupun pengetahuan dan keterampilan yang diajarkan sangat penting dan bermakna, tetapi diajarkan dengan cara yang tidak menarik bagi siswa, maka akan menimbulkan kegiatan belajar yang tidak efektif.

\section{METODE PENELITIAN}

Penelitian ini merupakan penelitian kualitatif. Dalam penelitian ini, pengumpulan data menggunakan teknik pengamatan dan teknik wawancara terhadap pemelajar BIPA [4]. Data bersumber dari tanggapan pemelajar yang mengikuti pogram yang dikemas dalam dua minggu dengan lima hari kegiatan pengajaran dalam seminggu. Di antara sepuluh hari kegiatan pengajaran terdapat kegiatan hari kegiatan real teaching dan satu karyawisata. Kegiatan ini merupakan kegiatan lepas yang dapat dipilih sendiri oleh peserta pada saat berada di Bandung. Kegiatan akhir minggu (Sabtu) yang tersedia berupa budaya ke Saung Angklung Mang Ujo, Tangkuban Perahu, membatik, dan bermain ke Komunitas Hong. Selain itu, pemelajar BIPA juga diperkenalkaan pula dengan lesson study.

\section{HASIL DAN PEMBAHASAN}

Pembelajaran BIPA berbasis budaya merupakan salah satu langkah yang dapat dilakukan terhadap orang asing. Melalui budaya mereka merasa tertarik dengan aneka keunikannya sehingga terbantu pula dalam menguasai bahasa Indonesia. Berinteraksi dengan budaya membantu pembelajar BIPA menyesuaikan diri di Indonesia. Lebih dari itu, pembelajaran BIPA berbasis budaya diharapkan membantu internasionalisasi bahasa dan budaya Indonesia, apalagi pemerintah Indonesia berharap bahasa Indonesia menjadi bahasa PBB. Pembelajar BIPA dapat mengenal bahasa dan budaya Indonesia dengan baik sehingga akan menjadi bekal bagi mereka untuk menetap di Indonesia. 
Brown menyatakan bahwa bahasa memiliki hubungan yang erat dengan kebudayaan[5]. Kebudayaan merupakan bagian yang integral pada interaksi antara bahasa dan pikiran. Pola kebudayaan, adat-istiadat, dan cara hidup manusia dinyatakan dengan bahasa. Pandangan dunia yang khas dinyatakan dalam bahasa dan bahasa sangat dipengaruhi oleh kebudayaan. Segala hal yang ada dalam kebudayaan akan tercermin di dalam bahasa. Hubungan bahasa dan kebudayaan memiliki hubungan yang saling mendukung [6].

Dengan demikian, bahasa memiliki peranan dalam suatu kebudayan karena pada dasarnya kebudayaan diekspresikan melalui bahasa. Apabila seseorang bercerita, secara tidak langsung akan terpancar budaya yang mempengaruhinya. Ia menyampaikan atau mengkomunikasikan ide-ide yang bersifat universal sebagai identitas budaya masyarakatnya. Demikian pula, apabila terjadi interaksi dalam proses pembelajaran bahasa Indonesia bagi penutur asing, sebenarnya kita mengajarkan budaya Indonesia kepada orang asing. Sekaitan pula dengan fungsi bahasa Indonesia sebagai alat pengembang kebudayaan, ilmu pengetahuan, dan teknologi [7][8].

\subsection{Implementasi Pembelajaran BIPA Berbasis Budaya}

Sesuai dengan pembicaraan pihak Kementrian Pendidikan dan Tenaga Kerja Singapura dengan UPI di Partere, program kerja sama ini dirancang khusus untuk menyediakan program yang memperkenalkan secara langsung model-model pembelajaran bahasa dan sastra Indonesia serta hazanah budaya Indonesia. Melalui program ini, peserta akan memperoleh pelatihan berbagai metode dan teknik serta implementasi pembelajaran bahasa Indonesia juga menikmati kesempatan untuk mengenal budaya Indonesia.

Kegiatan program ini dikemas untuk dua minggu dengan 5 hari kegiatan pengajaran dalam seminggu. Di antara 10 hari kegiatan pengajaran terdapat 2 hari kegiatan real teaching dan satu karyawisata. Jumlah jam pengajaran dalam kelas selama 5 hari adalah 22 $\frac{1}{2}$ jam @ 41/2 jam sehari. Setiap akhir pekan Kegiatan ini merupakan kegiatan lepas yang dapat dipilih sendiri oleh peserta pada saat berada di Bandung. Kegiatan akhir minggu (Sabtu) yang kami sediakan pembelajaran budaya ke Saung Angklun Mang Ujo, Tangkuban Perahu, membatik, dan bermain ke Komunitas HONG. Selain itu kami perkenalkaan pula pembelajaran denga lesson study.

\subsection{Respons Pembelajaran terhadap Pembelajaran BIPA Berbasis Budaya}

Proses pembelajaran BIPA sangat berkesan bagi para pengajar BIPA dari IPGK Singapura. Berikut ini paparan tanggapan tentang pengalaman mereka dalam pembelajaran bahasa Indonesia berbasis budaya.

1. Respons ketika awal pembelajaran

- Kerja sama dan tali silaturahim terjalin erat

- Perkongsian yang bermakna antara para guru kanan dan dosen dari UPI

- Perancangan susulan yang dilaksanakan dengan teliti

- Strategi pengajaran Bahasa Indonesia untuk mahasiswa asing seperti penggunaan Bahasa Inggeris yang minimal dan banyak penggunaan bahasa tubuh berkesan.

- Membuka mata dan kesedaran akan aspek nilai, kesopanan dan keramahan. Hal ini selaras dengan penekanan pada aspek nilai dalam kurikulum Singapura

- Informasi mengenai sistem pendidikan guru dan latihan guru di UPI sangat berguna

2. Respons ketika pembelajar mendapatkan materi di kelas

- Bahan atau material pengajaran yang disediakan lengkap 
- Perkongsian ilmu tentang kurikulum Bahasa Indonesia membawa banyak manfaat kepada para guru

- Pendekatan komunikatif digunakan bagi memperbaik pertuturan pelajar dalam Bahasa Indonesia.

- Pengajaran berpusatkan kepada pelajar-pelajar (student-centred) selaras dengan apa yang dilakukan di Singapura

- Keterampilan para guru penting kerana guru-guru menjadi 'role-model'

- Contoh-contoh kesilapan bahasa yang diberi sangat sesuai

- Kemudahan yang diberi sangat baik. Kebajikan kita para perserta terjaga

3. Respons terhadap pembelajaran puisi berbasis budaya

- Banyak aspek puisi dan contoh-contoh disentuh untuk mengukuhkan pemahaman

- Pendeklamasian beberapa puisi sangat berkesan

- Penerangan antara membaca dan mendeklarasi puisi.

- Contoh 'persembahan' puisi yang jarang dilihat seperti puisi rampak dan puisi muzikal menambah pengetahuan

- Pendekatan sastera sebagai suatu 'permainan' sangat menarik

- Pengajaran sastera perlu seronok agar senang diingati dan bahasa boleh dipelajari dalam suasana yang santai.

- Pengajaran - para guru yang terlalu mengongkong kreativiti pelajar melalui teguran dan kritik kepada pelajar boleh mematikan kreativiti pelajar

4. Respons terhadap pembelajaran seni lukis

- Pengetahuan mendalam dalam seni lukis dan tulisan, artefak yang dipamer dan bengkel yang dipersembahkan sangat berkesan

- Penggunaan musik latar boleh diterapkan dalam pengajaran dan pembelajaran

- Semangat, keikhlasan, kesungguhan dalam memperjuangkan sastera bertulis serta keinginan menyumbang kepada masyarakat sangat mengagumkan

- Penampilan dosen dengan penutup kepala berkesan dan menarik

- Keterampilan dan kemahiran guru dalam pengajaran seperti menyanyi, dan melagukan puisi menarik minat para pelajar

- Pembinaan paket pengajaran dalam aspek Folklore untuk mengajar Bahasa Melayu boleh diusahakan

5. Respons terhadap pembelajaran budaya Angklung

- Sambutan pemimpin sekolah sangat meriah - angklung, tarian merak, silat, persembahan slaid mengenai sekolah tersebut secara imbas

- Aspek kesantunan yang ditunjukkan, penyerapan nilai yang menyerlah ketika berinteraksi \& bersalaman dengan tetamu

- Jamuan enak dihidangkan, tempat solat disediakan

6. Respons terhadap pembelajaran dengan Lesson Study

- Penerangan tentang Lesson Study dan profil pelajar

- Para peserta/guru diberi tugas sebagai knowledgeable others untuk memerhati dan meneliti pembelajaran dan bagaimana murid mengikuti pengajaran dan pembelajaran

- Sekolah itu mengadaptasikan konsep LS untuk disesuaikan dengan kehendak / matlamat mereka

- Keberanian \& sikap keterbukaan guru menerima teguran/ komen membina 
- Fasilitator yang cemerlang (Ibu Erni) dapat membuat rumusan dengan baik sekali

- Guru yang mengendalikan pengajaran, walaupun guru pelatih, menunjukkan kebolehan dalam menjalankan pengajaran dan pembelajaran. Pengajaran aspek ICT (berkaitan dengan penulisan SMS yang efektif dan santun) berjalan dengan lancar dan autentik.

- Sebuah pengalaman yang membuka mata guru-guru. Sambutannya ramah, meriah, mesra dan penuh hormat

- Guru-guru dapat berinteraksi bukan sahaja bersama guru-guru dan pelajar-pelajar tetapi bersama para ibu bapak.

- Hubungan erat dan mesra di antara ibu bapa dan guru-guru juga sangat terserlah.

- Setiap bilik darjah telah di labelkan dengan nama pahlawan-pahlawan Indonesia untuk menanam rasa patriotik kepada negara

- Program "Kantin Kejujuran". Murid-murid dilatih dan diuji kejujuran mereka dengan diberi tanggungjawab untuk mengambil sendiri makanan yang disediakan lalu membayar tanpa dipantau.

- Kelas "program ekselerator" disediakan untuk pelajar yang mempunyai IQ 130 ke atas, di mana mereka di latih untuk menduduki peperiksaan SD pada tahun lima, bukan tahun enam

- Secara keseluruhan persekitaran sekolah yang tidak mengancam dan pelajar-pelajar kelihatan ceria dan gembira.

- Lawatan ke Pesta Ontel International telah mendedahkan kami dengan pelbagai persembahan budaya dan kesenian selain mempamerkan model-model basikal dari seluruh dunia. Selain itu persembahan tarian silat, pameran tentera Indonesia, serta pameran usahawan muda.

- Dermawisata ke Museum Geologi sangat memberi pengetahuan dan pengajaran yang luas.

7. Respons terhadap pembelajaran ke Komunitas HONG

- Guru memperoleh banyak maklumat tentang Komunitas HONG.

- Terdapat lebih daripada 800 permainan tradisional yang telah dikenal pasti, terdapat 80 permainan tradisional Singapura

- Bertujuan melestarikan dan mengembangkan produk mainan rakyat.

- Guru berpeluang melibatkan diri secara aktif membuat beberapa jenis permainan serta bermain lima jenis permainan secara berkumpulan.

- Guru mendapati bahawa (suasana santai, penerapan nilai bekerjasana, mengeratkan silaturrahim, unsur pertandingan dll.)

8. Respons terhadap pembelajaran ke Saung Angklung Mang Udjo, Museum \& Pendidikan

- Bengkel angklung sangat menarik. Guru meraih banyak maklumat dan pengalaman tentang angklung.

- Pembelajaran yang menarik dapat menanam sikap keinginan belajar sepanjang hayat.

9. Respons terhadap pembelajaran bahasa Indonesia di kelas workshop

- Tentang pengajaran bahasa yang harus direncanakan bagi menjalankan pengajaran dan pembelajaran yang efektif/berkesan. Namun sbg guru kita harus memastikan ada kefleksibelan terhadap pengajaran dan tidak statik, berdasarkan keupayaan guru dan keperluan murid kita.

- Penerangan ringkas bagaimana pengajaran Bahasa Indonesia itu dilaksanakan berdasarkan rancangan pengajaran (RPP) menambah pengetahuan 
- Contoh-contoh bahan pengajaran BI yang dihasilkan oleh para guru pelatih untuk pelajarpelajar BI yang bukan Indonesia. Ini memberi para guru kita beberapa cara menarik untuk mengajarkan BM melalui permainan-permainan yang menarik, termasuk mengajar para pelajar bukan Melayu.

- Pengajaran BI yang dijalankan untuk para pelajar bukan natif Indonesia secara 'penyerapan' atau 'full immersion' tanpa kaedah penterjemahan dilihat berkesan.

- Nyanyian lagu-lagu kanak-kanak menarik minat kanak-kanak untuk mempelajari bahasa boleh dimasukkan ke dalam bahan pengajaran BM di Singapura.

- Pengetahuan tentang cara atau formula Fry Graph untuk mengukur tahap kebacaan baik

- Demonstrasi yang agak terperinci mengenai teknik-teknik pengajaran Bahasa Indonesia yang digunakan di sekolah dasar dan sekolah menengah

- Demonstrasi cara-cara menggunakan lagu dan sastera untuk menarik minat murid-murid dan pengajaran Bahasa.

- Dengan menggunakan kaedah' ice-breaking', pengajaran bahasa tidak membosankan

- Alat-alat pengajaran seperti kad-kad pantun dan topeng-topeng yang ditunjukkan sangat baik dan menarik untuk pengajaran pantun dan bertutur.

- Murid-murid dapat mengapresiasi sastera dan pada masa yang sama dapat mempelajari Bahasa.

- Beliau berusaha untuk mendapatkan siswa-siswa dan pengajar untuk memuzikalisasikan puisi sebagai pengajarannya kerana beliau tidak begitu mahir dalam sastera dan puisi.

- Tiga cara pengajaran bahasa (melalui video Hellen Keller) ialah -eksperimentasi, ikonik dan simbolik. Kaedah ini amat baik digunakan terutama untuk murid-murid yang bukan berbangsa Melayu atau yang tidak boleh berbahasa Melayu.

- Video-video digunakan bagi memotivasi murid-murid dan juga digunakan sebagai rangsangan untuk pengajaran penulisan

- Pendekatan komunikatif dengan aktiviti-aktiviti 'hands-on' untuk menarik minat muridmurid.

10. Respons pembelajar terhadap pembelajaran Batik

- Para guru disambut mesra di makmal batik. Makanan ringan telah disiapkan seperti biasa malah diturunkan dari lantai 5 ke makmal di bawah.

- Pensyarah menceritakan sejarah batik Indonesia secara umum diikuti dengan perkembangan batiknya dengan jelas.

- Banyak corak motif suku kaum serta perkembangan motif dari prasejarah sehingga masa kini diperlihatkan menggunakan salindia dan video sebagai wadah untuk pengukuhan pemahaman para guru. Ini diikuti dengan pensyarah menunjukkan contoh-contoh yang ada di makmal tersebut sebagai contoh konkrit untuk menambah minat pendengar.

- Proses pembatikan diterangkan secara jelas melalui video. Teknik pembuatan membatik, langkah membuat batik dan perbezaan antara batik asli dan palsu merupakan suatu perkara yang para guru hargai.

- Ini diikuti dengan pelibatan para guru secara aktif dan amali membuat dua kerja tangan membatik iaitu, sapu tangan dan selendang.

- Tiga siswa telah memberikan pertolongan yang menyeluruh kepada para guru untuk mempersiapkan dua hasil kerja yang diberi.

Selain respons positif, mereka pun menyarankan hal-hal berikut. 
a. Lawatan ke tempat penanam pokok Mulberry - menghayati dan mengalami

b. Lawatan ke tempat-tempat budaya yang lain, di persekitaran Kota Bandung

c. Perubahan pada jadual program atau aturcara boleh diberitahu lebih awal

d. Lawatan ke sekolah SMP bagi Lesson Study - boleh melibatkan sesi refleksi bersama para guru dari Indonesia

e. Lawatan ke sekolah SD - lebih terancang dan boleh memerhati suasana bersekolah semasa masa kurikulum.

\section{SIMPULAN}

Berdasarkan pengalaman seni dan budaya, dapat dianalisis bahwa pembelajaran bahasa Indonesia berbasis budaya mampu menciptakan atmosfer komunikasi yang sarat dengan empati sehingga arah dan pendirian pribadi peserta didik (dalam hal ini guru IPGK) dapat dibimbing dan dikembangkannya. Selama interaksi tersebut berlangsung, instruktur (Dosen) merefleksikan pemikiran dan perasaan peserta didik. Dengan demikian, mereka menggunakan komentar yang reaktif, instruktur mampu membangkitkan kesadaran peserta didik terhadap persepsi dan perasaan mereka, lalu membantu mereka mengklarifikasi gagasan-gagasannya. Lebih jauh lagi instruktur mampu mengungkap dan menggali pengalaman peserta didik secara aktif.

\section{REFERENCES}

[1] O. S. Rivai, "Pemetaan Pengajaran Bahasa Indonesia bagi Penutur Asing (BIPA) di Asia," Jakarta, 2010.

[2] Kemenristekdikti, "Perguruan Tinggi Indonesia Diminati Mahasiswa Asing," 2017. [Online]. Available: https://ristekdikti.go.id/siaran-pers/perguruan-tinggi-indonesiadiminati-mahasiswa-asing-2/.

[3] Sulistiyo, "Model Pembelajaran Afiksasi Melalui Media Cakram Digital (Cd) Interaktif dalam Keterampilan Menulis Untuk Pembelajar Bahasa Indonesia Bagi Penutur Asing (Bipa) : Penelitian Eksperimen Subjek Tunggal Terhadap Siswa Kelas VII SMP Mutiara Nasional Internatio," Universitas Pendidikan Indonesia, 2012.

[4] L. J. Moleong, Metode Penelitian Kualitatif. Bandung: Remaja Rosdakarya, 2017.

[5] D. . Brown, Principles of Language Learning and Teaching. New York: Addison Wesley Longman Inc., 2000.

[6] F. Junaidi, R. Andhira, and E. Mustopa, "Implementasi Pembelajaran BIPA Berbasis Budaya sebagai Strategi Menghadapi MEA," in The 1st Education and Language International Conference Proceedings Center for International Language Development of Unissula, 2017, pp. 317-324.

[7] K. Saddhono, "Integrating culture in Indonesian language learning for foreign speakers at Indonesian universities," J. Lang. Lit., vol. 6, no. 2, 2015.

[8] K. Saddhono, "Cultural and Social Change of Foreign Students in Indonesia: The Influence of Javanese Culture in Teaching Indonesian to Speakers of Other Languages (TISOL)," in IOP Conference Series: Earth and Environmental Science, 2018, vol. 126, no. 1 . 